\title{
Development of models for simulation the influence of temperature on teliospores germination of Tilletia caries (DC.) Tul. \& C. Tul. and Tilletia laevis J.G. Kühn
}

\section{Opracowanie modeli do symulacji wpływu temperatury na kiełkowanie teliospor Tilletia caries (DC.) Tul. \& C. Tul. oraz Tilletia laevis J.G. Kühn}

\author{
Andrzej Wójtowicz*, Krzysztof Kubiak, Romuald Gwiazdowski, Maria Pasternak
}

\begin{abstract}
Summary
The development of models describing the influence of temperature on Tilletia laevis and Tilletia caries teliospores germination was the aim of the study conducted under laboratory condition. Teliospores were collected from infected ears of winter wheat Nadobna cultivar grown on the plots at the Experimental Stationon Institute of Plant Protection - National Research Institute in Winna Góra 60 kilometers south of Poznań. The water suspension of teliospores was plated on Petri dishes coated with a thin layer of water agar. Teliospores were incubated at the following temperature: 5, 10, 15, 20 and $25^{\circ} \mathrm{C}$. Teliospores germination varied depending on a temperature. The most germinated teliospores were observed at $15^{\circ} \mathrm{C}$ for $T$. caries and at 15 and $10^{\circ} \mathrm{C}$ for $T$. laevis. The germinated teliospores were not recorded at $25^{\circ} \mathrm{C}$. The relationship between the temperature and the germination of teliospores were expressed by a polynomials of the third degree. The models were used in the computer application designed to visualize the effect of temperature on the germination of spores of $T$. laevis and $T$. caries.
\end{abstract}

Key words: mathematical model; Tilletia laevis; Tilletia caries

\section{Streszczenie}

Celem przeprowadzonych badań było opracowanie modeli matematycznych opisujących wpływ temperatury otoczenia na kiełkowanie teliospor Tilletia laevis sprawcy śnieci gładkiej pszenicy oraz Tilletia caries sprawcy śnieci cuchnącej pszenicy. Teliospory pozyskiwano z porażonych kłosów pszenicy ozimej odmiany Nadobna, z poletek zlokalizowanych na terenie Polowej Stacji Doświadczalnej Instytutu Ochrony Roślin - Państwowego Instytutu Badawczego w Winnej Górze. Wodną zawiesinę zarodników nanoszono w równej objętości na płytki Petriego pokryte cienką warstwą agaru wodnego. Teliospory inkubowano w temperaturach: $5,10,15,20$ i $25^{\circ} \mathrm{C}$. Kiełkowanie teliospor było zróżnicowane w zależności od temperatury. Najwięcej skiełkowanych teliospor $T$. caries zaobserwowano w temperaturze $15^{\circ} \mathrm{C}$, a $\mathrm{T}$. laevis w temperaturach $15 \mathrm{i} 10^{\circ} \mathrm{C}$. W temperaturze $25^{\circ} \mathrm{C}$ nie odnotowano kiełkujących zarodników. Zależność między temperaturą a kiełkowaniem teliospor przedstawiono za pomocą wielomianów trzeciego stopnia, które wykorzystano przy opracowaniu aplikacji komputerowej przeznaczonej do wizualizacji wpływu temperatury na kiełkowanie zarodników T. laevis i T. caries.

Słowa kluczowe: model matematyczny; Tilletia laevis; Tilletia caries

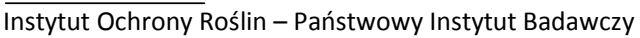

Władysława Węgorka 20, 60-318 Poznań

*corresponding author: a.wojtowicz@iorpib.poznan.pl 


\section{Wstęp / Introduction}

Temperatura obok wody, tlenu, dwutlenku węgla, substancji odżywczych i odczynu środowiska wymieniana jest w pierwszej kolejności wśród czynników modyfikujących kiełkowanie zarodników grzybów. Kiełkowanie zarodników warunkuje istotnie efektywność infekcji. Z tego powodu wyjaśnienie wpływu czynników środowiskowych na kiełkowanie zarodników od dawna stanowi tematykę licznych badań naukowych. Dużo uwagi w badaniach nad kiełkowaniem zarodników poświęca się między innymi znaczeniu temperatury. Temperatura bowiem decyduje o szybkości reakcji biochemicznych i reguluje tempo większości procesów fizjologicznych. Zazwyczaj minimalna temperatura wymagana do kiełkowania zarodników zawiera się w przedziale $0-10^{\circ} \mathrm{C}$. Istnieją jednakże grzyby np. rodzaju Sporotrichum, których zarodniki kiełkują w temperaturach ujemnych (Haines 1931). Optymalna temperatura kiełkowania zarodników licznych gatunków grzybów przyjmuje wartości od około 15 do ponad $40^{\circ} \mathrm{C}$, a maksymalna $\mathrm{w}$ niektórych przypadkach może przekroczyć $50^{\circ} \mathrm{C}$ (Weimer i Hater 1923). Duże zróżnicowanie pod względem wymagań termicznych grzybów występuje nie tylko między reprezentantami różnych typów, klas, rzędów oraz rodzin, ale również w obrębie jednego rodzaju. Przykładowo optymalna temperatura kiełkowania teliospor Tilletia controversa zawiera się w przedziale $2-5^{\circ} \mathrm{C}$, a Tilletia indica $12-20^{\circ} \mathrm{C}$ (Kryczyński i Weber 2011).

Tilletia laevis i Tilletia caries zaliczane są do patogenów, które w sprzyjających warunkach bez ochrony chemicznej stanowią poważny problem dla producentów pszenicy na świecie (Hoffmann i Waldher 1981). Straty w plonie wywołane porażeniem pszenicy przez te patogeny mogą osiągać około 25-30\% (Bamdadian 1993). Porażenie roślin zależy $\mathrm{w}$ dużym stopniu od temperatury warunkującej kiełkowanie zarodników i proces infekcji (Gottlieb 1950; Hyde 1982; Nazari i wsp. 2014).

W literaturze poświęconej $T$. caries i $T$. laevis brakuje bardziej szczegółowych i aktualnych informacji o roli temperatury w kolejnych etapach procesu infekcji. W celu uzupełnienia wiedzy na ten temat zostały podjęte badania ukierunkowane na opracowanie modelu matematycznego opisującego wpływ warunków termicznych na kiełkowanie teliospor T. caries i T. laevis.

\section{Materiały i metody / Materials and methods}

Doświadczenie przeprowadzono w warunkach laboratoryjnych. Teliospory $T$. laevis i $T$. caries pozyskiwano z porażonych kłosów pszenicy ozimej odmiany Nadobna, z terenu Polowej Stacji Doświadczalnej Instytutu Ochrony Roślin - Państwowego Instytutu Badawczego w Winnej Górze. Zarodniki odkażano w 5\% podchlorynie sodu. Czas odkażania wynosił 60 s. Po odkażeniu i po dwukrotnym przepłukaniu sterylną wodą, teliospory poddawano odwirowaniu. Następnie, sporządzono zawiesinę wodną, zawierającą około $1,2 \times 10^{7}$ teliospor w 1 mililitrze. Zawiesinę zarodników o objętości $100 \mu 1$ nanoszono pipetą automatyczną na płytki Petriego pokryte warstwą 2\% agaru wodnego. W celu zachowania jednakowego uwilgotnienia płytki umieszczono w szczelnych workach foliowych, a następnie inkubowano po dwie w temperaturach: 5, 10, 15,20 i $25^{\circ} \mathrm{C}$. Po pięciu dniach inkubacji przeprowadzono obserwację mikroskopową przy 200-krotnym powiększeniu. Na każdej płytce wybierano losowo 4 pola widzenia, a następnie w każdym z pól liczono kiełkujące teliospory. $\mathrm{Za}$ pomoca analizy wariancji $\mathrm{z}$ wykorzystaniem testu Tukeya oceniono na poziomie wynoszącym 0,05 istotność różnic między liczbami kiełkujących teliospor w analizowanych temperaturach. Zależność między temperaturą a intensywnością kiełkowania teliospor wyrażono za pomocą równań matematycznych.

Opracowanie równań poprzedzono obliczeniem względnych wartości kiełkujących teliospor obu analizowanych gatunków. W tym celu oddzielnie dla $T$. laevis i $T$. caries bezwzględne liczby kiełkujących teliospor podzielono przez największe liczby kiełkujących teliospor każdego $\mathrm{z}$ gatunków. Uzyskane $\mathrm{w}$ ten sposób względne wartości kiełkujących teliospor przekształcono dla każdej temperatury do postaci średnich. Tak przygotowane dane zastosowano do opracowania, z użyciem Pakietu Statistica 12, modeli matematycznych przeznaczonych do symulacji wpływu temperatury na kiełkowanie teliospor $T$. laevis i $T$. caries.

Następnie uzyskane modele wykorzystano przy opracowaniu aplikacji komputerowej przeznaczonej do wizualizacji wpływu temperatury na kiełkowanie zarodników $T$. laevis i $T$. caries. Aplikacja została opracowana z wykorzystaniem oprogramowania Delphi 32.

\section{Wyniki i dyskusja / Results and discussion}

W przeprowadzonym doświadczeniu wykazano istotny wpływ temperatury na kiełkowanie teliospor $T$. laevis i T. caries (tab. 1). W temperaturze 10 i $15^{\circ} \mathrm{C}$ odnotowano odpowiednio 4,6 i 5,7\% kiełkujących teliospor $T$. laevis. Istotnie mniej kiełkujących zarodników stwierdzono w pozostałych temperaturach. Zastosowanie temperatury $20^{\circ} \mathrm{C}$ spowodowało redukcję liczby kiełkujących zarodników do wartości $0,4 \%$, a $\mathrm{w}$ temperaturze $5^{\circ} \mathrm{C}$ odnotowano $0,2 \%$

Tabela 1. Wpływ temperatury na kiełkowanie teliospor Tilletia laevis i Tilletia caries

Table 1. The influence of temperature on germination of teliospores of Tilletia laevis and Tilletia caries

\begin{tabular}{c|c|c}
\hline \multirow{2}{*}{$\begin{array}{c}\text { Temperatura } \\
\text { Temperature } \\
{\left[{ }^{\circ} \mathrm{C}\right]}\end{array}$} & \multicolumn{2}{|c}{$\begin{array}{c}\text { Liczba kiełkujących teliospor } \\
\text { The number of germinated teliospores [\%] }\end{array}$} \\
\cline { 2 - 3 } & Tilletia laevis & Tilletia caries \\
\hline 5 & $0,2 \mathrm{~b}$ & $0,3 \mathrm{c}$ \\
\hline 10 & $4,6 \mathrm{a}$ & $2,4 \mathrm{~b}$ \\
\hline 15 & $5,7 \mathrm{a}$ & $3,9 \mathrm{a}$ \\
\hline 20 & $0,4 \mathrm{~b}$ & $2,1 \mathrm{~b}$ \\
\hline 25 & $0,0 \mathrm{~b}$ & $0,0 \mathrm{c}$ \\
\hline
\end{tabular}

W kolumnach jednakowymi literami oznaczono wartości nieróżniące się istotnie przy $\alpha=0,05$

Values in the columns followed by the same letter are not significantly different at $\alpha=0.05$ 
kiełkujących teliospor. $\mathrm{W}$ temperaturze $25^{\circ} \mathrm{C}$ nie zaobserwowano kiełkowania zarodników. Najwięcej kiełkujących teliospor T. caries stwierdzono w temperaturze $15^{\circ} \mathrm{C}$. Ich liczba wynosiła 3,9\% i była istotnie większa od odnotowanych w pozostałych temperaturach. Obniżenie temperatury do $10^{\circ} \mathrm{C}$ i podwyższenie do $20^{\circ} \mathrm{C}$ skutkowało istotnym zmniejszeniem liczby kiełkujących teliospor odpowiednio do wartości 2,4 i $2,1 \%$. W temperaturze $5^{\circ} \mathrm{C}$ stwierdzono zaledwie $0,3 \%$ kiełkujących teliospor, a w temperaturze $25^{\circ} \mathrm{C}$ zarodniki $T$. caries nie kiełkowały.

Rezultaty przeprowadzonych eksperymentów są zgodne z wynikami badań Purdyego i Kendricka (1963) nad wpływem temperatury i stopnia uwilgotnienia gleby na zakażenie pszenicy, w których wykazano, że infekcja pszenicy przez $T$. caries, w warunkach wystarczającego uwilgotnienia gleby zachodzi w zakresie od 5 do $25^{\circ} \mathrm{C}$. Interesujące wyniki badań nad wpływem temperatury na kiełkowanie teliospor $T$. caries i $T$. laevis przedstawił Lowther (1950), który oceniając przebieg badanego procesu w czasie, wykazał większe tempo kiełkowania teliospor $\mathrm{w}$ temperaturze $18-20^{\circ} \mathrm{C}$ niż $\mathrm{w}$ temperaturze $8-10^{\circ} \mathrm{C}$. Przeprowadzone przez tego autora doświadczenia zwracają także uwagę na różnicujący wpływ rasy patogena na kiełkowanie zarodników. Prezentowane natomiast przez Purdyego i Kendricka (1957) wyniki badań nad rasą T-5 T. caries, w których autorzy podają temperatury $10-15^{\circ} \mathrm{C}$ jako optymalne dla kiełkowania teliospor, a w zakresie $20-25^{\circ} \mathrm{C}$ odnotowują zmniejszenie efektywności analizowanego procesu znajdują potwierdzenie w wynikach doświadczeń przedstawionych w niniejszej pracy.

Wyniki przeprowadzonych doświadczeń wykorzystano do matematycznego opracowania wpływu temperatury na kiełkowanie teliospor analizowanych patogenów za pomocą następujących równań:

$\mathrm{Wk}$ Tla $=-2,80743+0,79395 \times \mathrm{T}+-0,05142 \times \mathrm{T}^{2}+$ $0,00096 \times \mathrm{T}^{3}\left(\mathrm{R}^{2}=90,3\right)$

$\mathrm{Wk} \mathrm{Tca}=-1,14634+0,29561 \times \mathrm{T}+-0,01175 \times \mathrm{T}^{2}+$ $0,000069 \times \mathrm{T}^{3}\left(\mathrm{R}^{2}=95,7\right)$

Wk Tla - wskaźnik kiełkowania $T$. laevis,

Wk Tca - wskaźnik kiełkowania $T$. caries,

$\mathrm{T}$ - temperatura,

$\mathrm{R}^{2}$ - współczynnik determinacji.

Wysokie wartości współczynników determinacji równań matematycznych opisujących wpływ temperatury na kiełkowanie zarodników wskazują na dobre dopasowanie opracowanych modeli do danych empirycznych. Pozytywna ocena dopasowania modeli do danych stanowiła przyczynek do opracowania aplikacji komputerowej służącej do wizualizacji relacji występującej między analizowanymi zmiennymi. Aplikacja umożliwia przedstawienie w formie wykresów liniowych i kolumnowych wpływu na kiełkowanie teliospor $T$. laevis i $T$. caries temperatury wprowadzanej skokowo $\mathrm{z}$ interwałem $1^{\circ} \mathrm{C}$ w zakresie od 1 do $25^{\circ} \mathrm{C}$. Wyniki przeprowadzonych symulacji na badanej populacji grzybów wskazują, że w temperaturze poniżej $5^{\circ} \mathrm{C}$ i powyżej $18^{\circ} \mathrm{C}$ kiełkowanie teliospor T. laevis jest mało prawdopodobne, a zakres kiełkowania $T$. caries wynosi od 5 do $24^{\circ} \mathrm{C}$ (rys. 1).

Zastosowanie modelu matematycznego do szacowania wpływu temperatury na kiełkowanie zarodników stanowi odbicie, licznie reprezentowanych w nauce, poglądów na prowadzenie badań nad rolą czynników środowiskowych w rozwoju patogenów (Waggoner i Parlange 1974, 1975; Pearson i wsp. 1977; Marín i wsp. 1998; Pardo i wsp. 2006; Nanguy i wsp. 2010; Schubert i wsp. 2010).

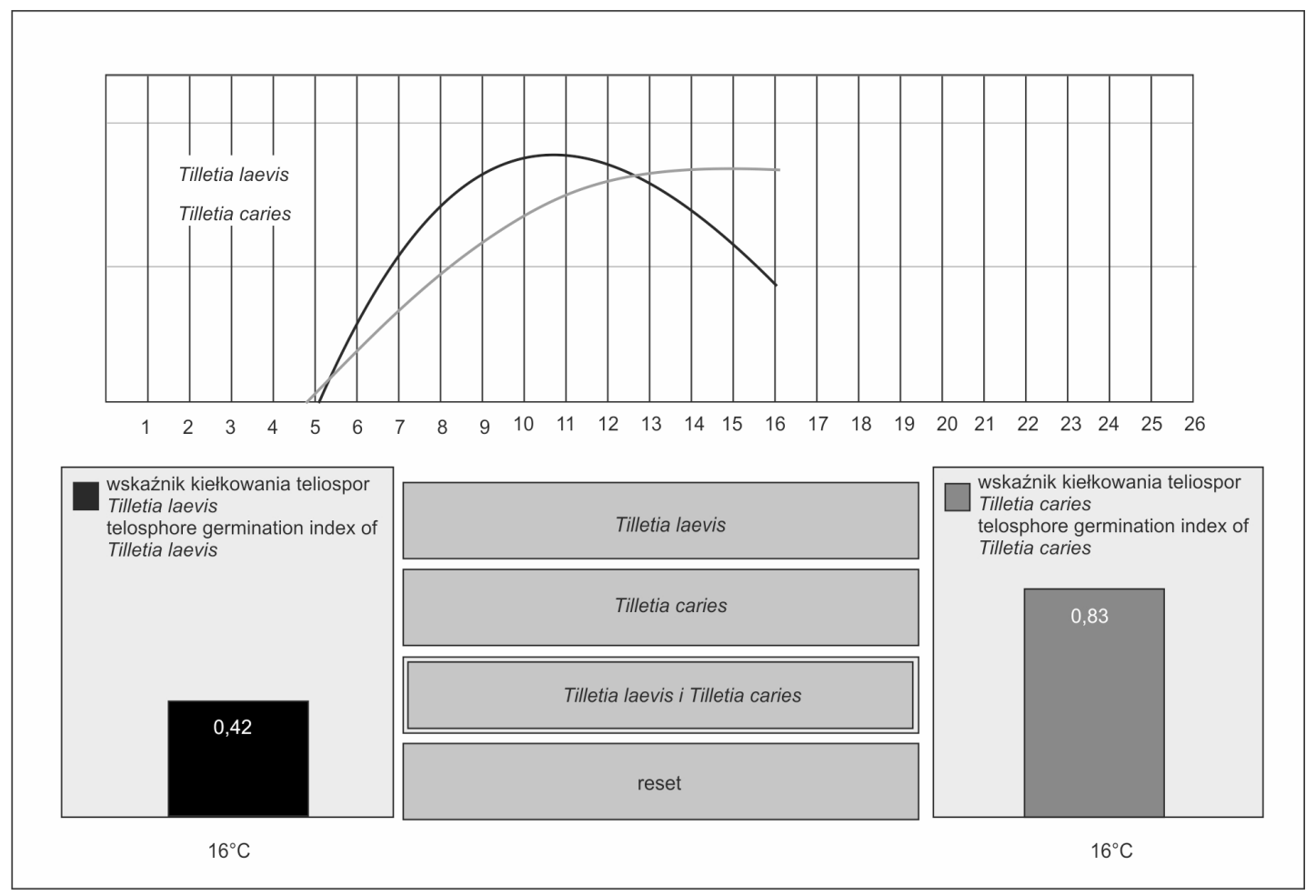

Rys. 1. Wizualizacja działania modelu kiełkowania teliospor Tilletia laevis i Tilletia caries

Fig. 1. Visualisation of Tilletia laevis i Tilletia caries teliospore germination models 


\section{Wnioski / Conclusions}

1. Odnotowany $\mathrm{w}$ doświadczeniu wpływ temperatury na kiełkowanie teliospor $T$. laevis i $T$. caries wskazuje na znaczenie tego czynnika w epidemiologii śnieci gładkiej pszenicy i śnieci cuchnącej pszenicy.
2. Wysoka wartość współczynnika determinacji równań matematycznych opisujących wpływ temperatury na kiełkowanie telispor $T$. laevis i $T$. caries świadczy o dobrym dopasowaniu opracowanych modeli do danych empirycznych.

\section{Literatura / References}

Bamdadian A. 1993. A short report on the wheat bunt in Iran. Plant Protection Research Institute. Evin, Iran, p. 2.

Gottlieb D. 1950. The physiology of spore germination in fungi. The Botanical Review 16: 229-257. DOI: 10.1007/BF02873609

Haines R.B. 1931. The influence of temperature on the rate of growth of Sporotrchium canis, from $-10^{\circ} \mathrm{C}$ to $+30^{\circ} \mathrm{C}$. Journal of Experimental Biology 8: 379-388.

Hoffmann J.A., Waldher J.T. 1981. Chemical seed treatments for controlling seedborne and soilborne common bunt of wheat. Plant Disease 65: 256-259.

Hyde P.M. 1982. Temperature-sensitive resistance of the wheat cultivar Maris Fundin to Puccinia recondita. Plant Pathology 31 (1): 25-30.

Kryczyński S., Weber Z. 2011. Fitopatologia. Tom 2. Choroby roślin uprawnych. PWRiL, Poznań, 464 ss.

Lowther C.V. 1950. Chlamydospore germination in physiologic races of Tilletia caries and Tilletia foetida. Phytopathology 40: 590-603.

Marín S., Sanchis V., Sáenz R., Ramos A.J., Vinas I., Magan N. 1998. Ecological determinants for germination and growth of some Aspergillus and Penicillium spp. from maize grain. Journal of Applied Microbiology 84 (1): 25-36.

Nanguy S.P.M., Perrier-Cornet J.-M., Bensoussan M., Dantigny P. 2010. Impact of water activity of diverse media on spore germination of Aspergillus and Penicillium species. International Journal of Food Microbiology 142 (1): 273-276. DOI: 10.1016/j.ijfoodmicro. 2010.06 .031

Nazari L., Pattori E., Terzi V., Morcia C., Rossi V. 2014. Influence of temperature on infection, growth, and mycotoxin production by Fusarium langsethiae and F. sporotrichioides in durum wheat. Food Microbiology 39: 19-26. DOI: 10.1016/j.fm.2013.10.009

Pardo E., Malet M., Marín S., Sanchis V., Ramos A.J. 2006. Effects of water activity and temperature on germination and growth profiles of ochratoxigenic Penicillium verrucosum isolates on barley meal extract agar. International Journal of Food Microbiology 106 (1): 25-31. DOI: 10.1016/j.ijfoodmicro.2005.07.002

Pearson R.C., Aldwmcke H.S., Seem R.C. 1977. Teliospore germination and basidiospore formation in Gymnosporangium juniperivirginianae: a regression model of temperature and time effects. Canadian Journal of Botany 55: 2832-2837.

Purdy L.H., Kendrick E.L. 1957. Influence of environmental factors on the development of wheat bunt in the Pacific Northwest. I. Effect of soil moisture and soil temperature on spore germination. Phytopathology 47: 591-594.

Purdy L.H., Kendrick E.L. 1963. Influence of environmental factors on the development of wheat bunt in the Pacific Northwest. VI. Effect of soil temperature and moisture on infection by soil spores. Phytopathology 53: 416-418.

Schubert M., Mourad S., Schwarze F.W.M.R. 2010. Statistical approach to determine the effect of combined environmental parameters on conidial development of Trichoderma atroviride (T-15603.1). Journal of Basic Microbiology 50 (6): 570-580. DOI: $10.1002 /$ jobm.201000036

Waggoner P.E., Parlange J.Y. 1974. Mathematical model for spore germination at changing temperature. Phytopathology 64: 605-610.

Waggoner P.E., Parlange J.Y. 1975. Slowing of spore germination with changes between moderately warm and cool temperatures. Phytopathology 65 (5): 551-553.

Weimer J.L., Hater L.L. 1923. Temperature relations of eleven species of Rhizopus. Journal of Agricultural Research 24: 1-40. 